\title{
Comparison of crown width, length, width/length ratio of maxillary anterior teeth between male and female dental students
}

\author{
Pak Han Yuan*, Ida Ayu Evangelina*, Gita Gayatri* \\ *Departement Of Orthodontics Faculty of Dentistry Universitas Padjadjaran, Indonesia
}

\begin{abstract}
Introduction: Crown width and crown length provides significant information on human evolution as well as in forensic and clinical dentistry. The width-to-length ratio or individual tooth proportion (ITP) of maxillary anterior teeth considered as an important factors for dental aesthetics and harmonic teeth arrangement. The goal of this research is to establish if there is any significant difference in crown width, length, width/length ratio of permanent maxillary anterior teeth between male and female students in Faculty of dentistry Padjadjaran University Bandung, Indonesia. Method: The method used for this research was analytical statistical approach. Total sampling technique with criteria was used to determine the sample size from the total population of students of Faculty of Dentistry Padjadjaran University from batch 2012 to 2014. The data was analyzed using Kolmogorov-Smirnov test, Independent Two Sample T test and Mann-Whitney test. Result: there is difference in crown width, length, width/length ratio of permanent maxillary anterior teeth between male and female students in Faculty of Dentistry Padjadjaran University. Conclusion: There is significant difference in crown width and length of permanent maxillary anterior teeth between male and female students in Faculty of Dentistry Padjadjaran University, but there is no significant difference in crown width/length ratio of permanent maxillary anterior teeth between male and female students in Faculty of Dentistry Padjadjaran University Bandung, Indonesia.
\end{abstract}

Keywords: Crown Width, Length, Width/length

P-ISSN 1979-0201, e-ISSN 2549-6212 Available from:http://jurnal.unpad.ac.id/pjd/article/view/19275

DOI:https://dx.doi.org/10.24198/pjd.vol30no3.19275

Submission:Aug 04, 2017; Reviewed: Apr 04,2018; Resubmit for review: Oct 04, 2018 Accepted: Sep 18, 2018; Published online: Nov 30, 2018

\section{INTRODUCTION}

Maxillary anterior teeth are essential for esthetics in Orthodontics, Prosthodontics and other restorative patients and it is considered the most dominant element in anterior dental esthetics since they are the most visible teeth during facial activity. ${ }^{1,2}$ The teeth size, shape, and arrangement are the most influential factor for harmonious appearance. ${ }^{3,4}$ Therefore, the size and form of the maxillary anterior teeth are important not only to dental esthetics, but also to facial esthetics. ${ }^{5,6}$

Corresponding author: Gita Gayatri, Department of Orthodontics Faculty of Dentistry Universitas Padjadjaran, indonesia M: +262 8782223 3418; email: gita.gayatri@fkg.unpad.ac.id. 
The important anatomic feature of teeth is its dimensions, which is important in dental esthetics and also is an important factor in restoration treatments and orthodontic space estimations. There are three important aspects of dimensions which are width, length, and the ratio of widthto-length. ${ }^{7}$

There is accumulated evidence indicates that maxillary anterior tooth dimension can vary according to various factors like: sexual dimorphism, race, genetics, and environment, so it may vary significantly among individuals and between populations. ${ }^{8,9}$ The diversity in teeth is evident among human populations and variations in dental crown size have been reported between gender. ${ }^{10,11}$

Several studies have shown that there are morphological and developmental differences in the dentition of males and females. ${ }^{11}$

There are three divisions of esthetics in Orthodontics presented by Sarver and Ackerman that are macro esthetics, mini esthetics, and micro esthetics. ${ }^{12}$ Macro esthetics refers to the face, its harmony and proportions, and the esthetic impact of the several structures in its composition whereas mini esthetics includes the smile framework, how teeth are exposed and perceived in smile dynamics, specially its relation with the lips. The focus of this study is the approach of micro esthetics, especially on teeth dimensions and proportions in height and width, with its variations. ${ }^{12,13}$

\section{METHODS}

The current study was a statistical analytic research with cross-sectional survey done on the sample from the population to collect data. The study population of this research is primary data from dental casts of batch 2012 to 2014 students of Faculty Of Dentistry Padjadjaran University in Orthodontic laboratory. This research sampling method is total population sampling.

The sample size will be all the dental casts that fulfil the following Inclusion criteria arevdental casts from subjects of deutero melayu race, dental casts of the subjects with anterior teeth erupted equally and sufficiently for measurement, dental casts of batch 2012 to 2014 students in Faculty Of Dentistry Padjadjaran University, dental casts which are in good condition and Exclusion Criteria are dental casts of the subjects with missing or restored maxillary anterior teeth, dental casts of the subjects with abnormality of tooth structure, dental casts of the subjects with history of orthodontic treatment, dental casts of the subjects with interdental crowding in maxillary anterior teeth, dental casts of the subjects with intruded, extruded or rotated teeth in anterior region, dental casts of the subjects with gingival enlargement and gingival recession.

Research procedure divided into preparation and execution. Preparation procedure are informed consent was obtained from the students of batch 2012 to 2014 in Faculty Of Dentistry Padjadjaran University before measuring dental casts. Screening dental casts secondary data in Orthodontic laboratory of Faculty Of Dentistry Padjadjaran University to make sure that all the dental casts are fulfilled with the inclusion and exclusion criteria. All measurements are carried out by a single examiner to eliminate interobserver error. All measurements are taken three times during the study for each measurement to avoid intra-observer error. Execution procedur are mesiodistal width and incisocervical length of the right maxillary central incisor, lateral incisor and canine were measured on dental casts using a digital vernier caliper to the nearest $0.01 \mathrm{~mm}$. The mesiodistal distance is measured with the calipers held parallel to the occlusal and buccal surfaces and held perpendicular to the long axis of the crown. The length of tooth crown is measured with calipers held parallel to long axis, between most cervical extension of the tooth and most incisal point of anatomical crown. All measurements are taken three times during the study for each measurement by the same operator and with the same equipment.

Data statistical analysis using statistical Package for Social Science (SPSS) version 20 was used to determine mean crown width and crown length, standard deviation, and the crown width/ length ratio of right maxillary anterior teeth were calculated for each group and computed. A normality test, Kolmogrov-Smirnov test is done to test the numerical variables of assessing normality. Independent 2 sample t-test is done if the data is normal distribution and Mann Whitney $U$ test is used if the data is non-normally distributed. Both 
tests were performed to determine whether there were gender differences in the incidence of the crown width, length and width/length ratio of each tooth group. The level of significance was established as $\mathrm{P}<0.05$ for all statistical evaluation.

\section{RESULTS}

The value of mean crown width of maxillary lateral incisor of male is $7.46 \mathrm{~mm}$ while $6.99 \mathrm{~mm}$ for female in this study. Previous studies reported the mean mesiodistal width lateral incisors varied in range from $5.5 \mathrm{~mm}$ to $8 \mathrm{~mm}^{14}$, crown width of maxillary lateral incisor of female and male student of Faculty Of Dentistry Padjadjaran University in the range of $5.5 \mathrm{~mm}$ to $8 \mathrm{~mm}$ when compare to previous studies (Table 1 ).

The value of mean crown width of maxillary canine of male is $8.37 \mathrm{~mm}$ while $7.87 \mathrm{~mm}$ for female (Table 1). Previous studies reported the mean mesiodistal width of maxillary canine ranging from $6.5 \mathrm{~mm}$ to $9 \mathrm{~mm} .{ }^{14}$ From the comparison with previous study, the results show that female and male student in Faculty Of Dentistry Padjadjaran University have slightly greater mesiodistal tooth size.

The results obtained from this study showed from table 2 that the value of mean crown length of maxillary central incisor of male is $9.81 \mathrm{~mm}$ while $9.41 \mathrm{~mm}$ for female in this study. While in previous study, the results showed that crown length of female maxillary central incisor ranging from $9.14 \mathrm{~mm}$ to $9.26 \mathrm{~mm}$ and male's ranging from $10.1 \mathrm{~mm}$ to $10.32 \mathrm{~mm} .{ }^{2}$ From the comparison with previous study, the results show that female student in Faculty Of Dentistry Padjadjaran University have slightly greater mesiodistal tooth size while male in the range.

In this study, mean length of maxillary lateral incisor of male is $8.41 \mathrm{~mm}$ while $8.06 \mathrm{~mm}$ for female (Table 2). Previous studies reported the mean length of maxillary lateral incisor ranging from $6.77 \mathrm{~mm}$ to $9.10 \mathrm{~mm} .{ }^{15}$ The results obtained from this study the mean crown length of maxillary canine of male is $9.32 \mathrm{~mm}$ and $8.92 \mathrm{~mm}$ for female in in this study (Table 2). While in previous study, the results showed that crown length of maxillary canine ranging from $8.96 \mathrm{~mm}$ to $11.93 \mathrm{~mm} .{ }^{15}$

The result of this study showed from table 3 that the width/length ratio of maxillary central incisor for male is $89.47 \%$ and $90.66 \%$ for female. While from the previous study the mean of clinical tooth crown width/length ratio for central incisor of male versus female is $88.7 \%$ versus $91.2 \% .{ }^{5}$ From the comparison with previous study, the results show that male student in Faculty Of Dentistry Padjadjaran University have higher tooth crown width/length ratio while female have lower width/ length ratio. From the statement above, female crown width/length ratio is higher than male this indicate that male have more rectangular teeth shape compare to female.

The width/length ratio of maxillary lateral incisor of male is $89.25 \%$ and $87.27 \%$ for female (Tabel 3). Previous study reported that the mean of clinical tooth crown width-to-length ratios of maxillary canine for male versus female $84.1 \%$ versus $83.4 \% .{ }^{5}$ From the comparison with previous study, the results show that male and female students in Faculty Of Dentistry Padjadjaran University have higher tooth crown width/length ratio. From the statement above, the results show that male have higher percentage compare to female and this can indicate that female display a more rectangular teeth shape compare to male.

The width/length ratio of right maxillary canine of male is $90.20 \%$ while $88.70 \%$ for female in this study. In the previous study, the mean of clinical tooth crown width-to-length ratios of maxillary canine for male versus female is $89.4 \%$ versus $87.3 \% .^{5}$ From the comparison with previous study, the results show that male and female students in Faculty Of Dentistry Padjadjaran University have higher tooth crown width/length ratio. From the statement above, the results show that male have higher percentage compare to female and this can indicate that female display a more rectangular teeth shape compare to male.

The results of the independent two sample $t$ test is shown in Table 4 showed that the crown width and length have significant difference between male and female student in Faculty Of Dentistry Padjadjaran University. From previous study among the Chilean population, the width and length of maxillary anterior teeth showed statistically significant sex differences between males and females, indicating that they are sexually dimorphic. ${ }^{11}$

From other previous studies have also reported that the existence of significant 
Table 1. Data of width of right maxillary central, lateral and canine incisor

\begin{tabular}{ccccc}
\hline Teeth & Gender & Sample size $(\mathrm{n})$ & Mean crown width (mm) & Standard deviation (sd) \\
\hline \multirow{2}{*}{ Right maxillary central } & Male & 39 & 8.81 & 0.52 \\
& Female & 88 & 8.50 & 0.56 \\
\multirow{3}{*}{ Right maxillary lateral } & Male & 39 & 7.46 & 0.40 \\
& Female & 88 & 6.99 & 0.63 \\
\multirow{2}{*}{ Right maxillary canine } & Male & 39 & 8.37 & 0.51 \\
& Female & 88 & 7.87 & 0.52 \\
\hline
\end{tabular}

Table 2. Data of length of right maxillary central, lateral, canine incisor

\begin{tabular}{ccccc}
\hline Teeth & Gender & Sample size $(\mathrm{n})$ & Mean crown length $(\mathrm{mm})$ & Standard deviation (sd) \\
\hline \multirow{2}{*}{ Right maxillary central } & Male & 39 & 9.81 & 0.52 \\
& Female & 88 & 9.41 & 0.56 \\
\multirow{2}{*}{ Right maxillary lateral } & Male & 39 & 8.41 & 0.40 \\
\multirow{2}{*}{ Right maxillary canine } & Female & 88 & 8.06 & 0.63 \\
& Male & 39 & 9.32 & 0.83 \\
& Female & 88 & 8.92 & 0.77 \\
\hline
\end{tabular}

Table 3. Data of width/length ratio of right maxillary central,lateral and canine incisor

\begin{tabular}{ccccc}
\hline Teeth & Gender & Sample size $(\mathrm{n})$ & W/I ratio $(\%)$ & Standard deviation (sd) \\
\hline \multirow{2}{*}{ Right maxillary central } & Male & 39 & 89.47 & 6.87 \\
& Female & 88 & 90.66 & 7.05 \\
\multirow{2}{*}{ Right maxillary lateral } & Male & 39 & 89.25 & 7.22 \\
& Female & 88 & 87.27 & 8.36 \\
\multirow{2}{*}{ Right maxillary canine } & Male & 39 & 90.20 & 6.72 \\
& Female & 88 & 88.70 & 7.73 \\
\hline
\end{tabular}

Table 4. Independent two sample t test of crown width and crown length

\begin{tabular}{ccccccc}
\hline \multicolumn{2}{c}{ Independent two sample t test of crown width } & \multicolumn{3}{c}{ Independent two sample t test of crown length } \\
\hline Tooth & T & Df & P value & T & Df & P value \\
\hline Mci & 2.866 & 125 & 0.005 & 2.675 & 125 & 0.008 \\
Mli & 4.267 & 125 & 0.000 & 2.477 & 125 & 0.015 \\
MC & 5.045 & 125 & 0.000 & 2.671 & 125 & 0.009 \\
\hline
\end{tabular}

Table 5. Independent two sample $t$ test of crown w/l ratio

\begin{tabular}{cccc}
\hline Tootha & $\mathrm{t}$ & $\mathrm{df}$ & $\mathrm{P}$ value \\
\hline $\mathrm{MCl}$ & -0.884 & 123 & 0.378 \\
$\mathrm{MC}$ & 1.047 & 125 & 0.297 \\
\hline
\end{tabular}

differences between male and female's tooth size usually shows that male display 2-6\% larger teeth compare to female for crown dimensions. ${ }^{11,16,17}$ Forensic science and archaeology. Sexual dimorphism in the morphometric crown traits of the deciduous dentition may be used to help resolve this issue. Dental stone casts from a
Table 6. Mann-whitney u test of crown w/l ratio

\begin{tabular}{cc}
\hline & Maxillary lateral incisor \\
\hline$P$ value & 0.340 \\
\hline
\end{tabular}

Amci indicates maxillary central incisor; $\mathrm{mc}$, maxillary canine

European derived Australian sample $(n=151)$. This statement can be supported by this study, the results obtained showed the mean crown width and length of male is larger compare to female.

The result of current study revealed there is no significant $(p>0.05)$ differences between gender in width-to-length ratio of maxillary anterior 
teeth in Table 5 by independent two sample t test and Mann-Whitney $\mathrm{u}$ test. This is supported by previous study, results showed that although there is an increased in width and length of maxillary central incisor in male, but there is only a minimal difference was found between the sexes with respect to tooth width-to-height ratios. ${ }^{1}$ As for this reason, the crown width-to-length ratio was accepted to be the most stable reference because it had minimum variation between genders. ${ }^{18}$

The width of lateral incisor both genders, length of central incisor of males, length of lateral incisor and canine of both genders data obtained from this study are in the range when compared to the previous studies.

Comparison between the data obtained in this study and previous studies, Faculty of Dentistry Padjadjaran University students have larger teeth in term of width of central incisor and canine for genders, length of central incisor for female and width/length ratio of maxillary anterior teeth due to the different race and environment and data that was obtained, the mean of widthto-length ratio for male canine $(90.20 \%)$, central incisor (89.47\%), lateral incisor (89.25\%), while for female central incisor $(90.66 \%)$, canine $(88.70 \%)$, lateral incisor

\section{DISCUSSION}

This study was conducted to compare the width, length and width/length ratio of maxillary anterior teeth between male and female student of Faculty Of Dentistry Padjadjaran University. The size and ratio of the maxillary anterior teeth especially when perceived from front have considerable implications for esthetic diagnosis and treatment planning. These have an effect on the space availability, stability of dentition, esthetics and health of the periodontium. ${ }^{9}$

This study was undertaken using measurement on dentals casts of students in Faculty Of Dentistry Padjadjaran University from batch 2012 to 2014. The sample consists of 39 males' dental casts and 88 females' dental casts which filled the criteria. A digital vernier caliper with least count 0.01 was used to record the measurement precisely.

In the present study, the results obtained showed from table 1 that the value of mean crown width of maxillary central incisor of male is $8.81 \mathrm{~mm}$ while 8.50 for female. Previous studies reported the mean mesiodistal width of female maxillary central incisor ranging from $8.16 \mathrm{~mm}$ to $8.23 \mathrm{~mm}$. Mean mesiodistal width of male maxillary central incisor ranging from $8.43 \mathrm{~mm}$ to 8.47 $\mathrm{mm} .^{2}$ From the comparison with previous study, the results show that female and male student in Faculty of Dentistry Padjadjaran University have slightly greater mesiodistal tooth size.

The results obtained from this study showed from table 2 that the value of mean crown width of maxillary lateral incisor of male is $7.46 \mathrm{~mm}$ while $6.99 \mathrm{~mm}$ for female in this study. Previous studies reported the mean mesiodistal width lateral incisors varied in range from $5.5 \mathrm{~mm}$ to 8 mm. ${ }^{14}$

In the present study, the results obtained from the Table 3 showed that the value of mean crown width of maxillary canine of male is 8.37 $\mathrm{mm}$ while $7.87 \mathrm{~mm}$ for female. Previous studies reported the mean mesiodistal width of maxillary canine ranging from $6.5 \mathrm{~mm}$ to $9 \mathrm{~mm} .{ }^{14}$ From the comparison with previous study, the results show that female and male student in Faculty of Dentistry Padjadjaran University have slightly greater mesiodistal tooth size.

From table 4 that the value of mean crown length of maxillary central incisor of male is 9.81 $\mathrm{mm}$ while $9.41 \mathrm{~mm}$ for female in this study. While in previous study, the results showed that crown length of female maxillary central incisor ranging from $9.14 \mathrm{~mm}$ to $9.26 \mathrm{~mm}$ and male's ranging from $10.1 \mathrm{~mm}$ to $10.32 \mathrm{~mm} .^{2}$ From the comparison with previous study, the results show that female student in Faculty of Dentistry Padjadjaran University have slightly greater mesiodistal tooth size while male in the range.

In this study, the results obtained showed from table 5 that mean length of maxillary lateral incisor of male is $8.41 \mathrm{~mm}$ while $8.06 \mathrm{~mm}$ for female. Previous studies reported the mean length of maxillary lateral incisor ranging from $6.77 \mathrm{~mm}$ to $9.10 \mathrm{~mm} .{ }^{15}$

The results obtained from this study showed from table 6 that the mean crown length of maxillary canine of male is $9.32 \mathrm{~mm}$ and $8.92 \mathrm{~mm}$ for female in in this study. While in previous study, the results showed that crown length of maxillary canine ranging from $8.96 \mathrm{~mm}$ to $11.93 \mathrm{~mm} .{ }^{15}$ 
The result of this study showed from table 7 that the width/length ratio of maxillary central incisor for male is $89.47 \%$ and $90.66 \%$ for female. While from the previous study the mean of clinical tooth crown width/length ratio for central incisor of male versus female is $88.7 \%$ versus $91.2 \% .{ }^{5}$ From the comparison with previous study, the results show that male student in Faculty Of Dentistry Padjadjaran University have higher tooth crown width/length ratio while female have lower width/ length ratio. From the statement above, female crown width/length ratio is higher than male this indicate that male have more rectangular teeth shape compare to female.

In present study, the results obtained showed from table 8 that the width/length ratio of maxillary lateral incisor of male is $89.25 \%$ and $87.27 \%$ for female. Previous study reported that the mean of clinical tooth crown width-to-length ratios of maxillary canine for male versus female $84.1 \%$ versus $83.4 \% .^{5}$ From the comparison with previous study, the results show that male and female students in Faculty Of Dentistry Padjadjaran University have higher tooth crown width/length ratio. From the statement above, the results show that male have higher percentage compare to female and this can indicate that female display a more rectangular teeth shape compare to male.

The results of this study showed from table 9 that the width/length ratio of right maxillary canine of male is $90.20 \%$ while $88.70 \%$ for female in this study. In the previous study, the mean of clinical tooth crown width-to-length ratios of maxillary canine for male versus female is $89.4 \%$ versus $87.3 \% .^{5}$ From the comparison with previous study, the results show that male and female students in Faculty Of Dentistry Padjadjaran University have higher tooth crown width/length ratio. From the statement above, the results show that male have higher percentage compare to female and this can indicate that female display a more rectangular teeth shape compare to male.

The results of the independent two sample $t$ test is shown in Table 5 and Table 6 , and can conclude that the crown width and length have significant difference between male and female student in Faculty of Dentistry Padjadjaran University. From previous study among the Chilean population, the width and length of maxillary anterior teeth showed statistically significant sex differences between males and females, indicating that they are sexually dimorphic. ${ }^{11}$

From other previous studies have also reported that the existence of significant differences between male and female's tooth size usually shows that male display 2-6\% larger teeth compare to female for crown dimensions. ${ }^{11,16,17}$ This statement can be supported by this study, the results obtained showed the mean crown width and length of male is larger compare to female.

The result of current study revealed there is no significant $(p>0.05)$ differences between gender in width-to-length ratio of maxillary anterior teeth in Table 5 and Table 6 by independent two sample $t$ test and Mann-Whitney u test. This is supported by previous study, results showed that although there is an increased in width and length of maxillary central incisor in male, but there is only a minimal difference was found between the sexes with respect to tooth width-to-height ratios. ${ }^{1}$ As for this reason, the crown width-to-length ratio was accepted to be the most stable reference because it had minimum variation between genders. ${ }^{18}$

From the table 1 to table 6 showed the data of width and length of right maxillary anterior teeth. Normality test is done to determine if the data collected from the dental casts is normally distributed. If the data is normally distributed, it is said to be non-biased. If data deviated from normal distribution, it is said to be biased. The normality tests used in this research is KolmogorovSmirnov test, results of the test is showed in table 5.

The distribution of data determined by normality tests is found to be normally distributed, and can be continue using independent 2 sample t-test to evaluate if the width and length of two genders have significant difference or not. The result of the test is shown in table 5, and can conclude that crown width and length have significant difference between male and female student in FKG UNPAD. From previous study among the Chilean population, the width and length of maxillary anterior teeth showed statistically significant sex differences between males and females, indicating that they are sexually dimorphic. ${ }^{11}$

For maxillary anterior teeth, the crown width-to-length ratio was accepted to be the most stable reference because it had minimum 
variation between gender or between teeth. ${ }^{19}$ The mean of clinical tooth crown width-to-length ratios for male versus female, respectively, were as follows: central incisor, $88.7 \%$ versus $91.2 \%$; lateral incisor, $82.1 \%$ versus $83.4 \%$; and canine, $83.4 \%$ versus $87.3 \% .^{5}$ In the present study, the mean width to length ratio of maxillary right central incisor for male and female are $89.47 \%$ and $90.66 \%$ respectively, the mean width to length ratio of maxillary right lateral incisor for male is $89.25 \%$ while female is $87.27 \%$, the mean width to length ratio of maxillary right canine for male and female are $90.20 \%$ and $88.70 \%$ respectively. That is, the width- to-length ratios of the maxillary anterior teeth in both genders were found to be greater than those suggested in previous studies.

The result of current study revealed there is a slightly difference but no significant $(p>0.05)$ differences between gender in width-to-length ratio of maxillary anterior teeth. This is supported by previous study, results showed that although there is an increased in width and length of maxillary central incisor in male, but there is only a minimal difference was found between the sexes with respect to tooth width-to-height ratios. ${ }^{1}$ From the data obtained, the mean of width-to-length ratio for male canine $(90.20 \%)>$ central incisor $(89.47 \%)>$ lateral incisor $(89.25 \%)$, while for female central incisor $(90.66 \%)>$ canine $(88.70 \%)>$ lateral incisor $(87.27 \%)$.

\section{CONCLUSION}

There is significant difference in crown width and length of permanent maxillary anterior teeth between male and female students in Faculty of Dentistry Padjadjaran University, but there is no significant difference in crown width/length ratio of permanent maxillary anterior teeth between male and female students in Faculty of Dentistry Padjadjaran University Bandung, Indonesia.

\section{REFERENCES}

1. Radia S, Sherriff $M$, McDonald F, Naini FB. Relationship between maxillary central incisor proportions and facial proportions. J Prosthet Dent 2016 Jun;115(6):741-8. doi: 10.1016/j. prosdent.2015.10.019

2. Vadavadagi V S, Hombesh MN, Choudhury
Krishna G, Deshpande S, Anusha C V, Murthy DK. Variation in size and form between left and right maxillary central incisor teeth. J Int oral Heal JIOH. 2015;7(2):33-6.

3. Meenu M, Abraham P, Abraham ST. Golden proportion in denture esthetics. Heal Sci. 2013;2(1):1-10.

4. Sandeep N, Satwalekar P, Srinivas S, Reddy CS, Reddy GR, Reddy BA. An Analysis of Maxillary Anterior Teeth Dimensions for the Existence of Golden Proportion: Clinical Study. J Int oral Heal JIOH 2015;7(9):18-21.

5. Hasanreisoglu U, Berksun S, Aras K, Arslan I. An analysis of maxillary anterior teeth: Facial and dental proportions. J Prosthet Dent 2005;94(6):530-8.

6. Al-Marzok MI, Majeed KRA, Ibrahim IK. Evaluation of maxillary anterior teeth and their relation to the golden proportion in Malaysian population. BMC Oral Health 2013;13(1):1-5.

7. Ghasemi T, Kaviani R, Mackinejad A, Radmehr O, Kazemi M, Kavoli S. The width to height ratio of clinical crown of maxillary anterior teeth in iranians. Int $\mathrm{J} \mathrm{Adv} \mathrm{Biotechnol} \mathrm{Res}$ 2016;7(3):1182-9.

8. Hattab FN, Al-Khateeb S, Sultan I. Mesiodistal crown diameters of permanent teeth in Jordanians. Arch Oral Biol 1996;41(7):641-5.

9. Alhabahbah $\mathrm{AM}$, Aburumman KK, AlShamout R, Wasfi A Almanaseer, Zyod Al. Evaluating the validity of mathematical proportions in maxillary anterior teeth in jordanian population. Pakistan Oral Dent $\mathrm{J}$ 2016;36(2):295-301.

10. Brook AH, Griffin RC, Townsend G, Levisianos Y, Russell J, Smith RN. Variability and patterning in permanent tooth size of four human ethnic groups. Arch Oral Biol 2009;54:79-85.

11. Peckmann TR, Logar C, Garrido-Varas CE, Meek S, Pinto XT. Sex determination using the mesio-distal dimension of permanent maxillary incisors and canines in a modern Chilean population. Sci Justice 2016;56(2):849.

12. Carlos R, Brandao B, Bustamente L, Brandao C. Finishing procedures in Orthodontics:dental dimensions and proportions(microesthetics ). Dent Press J orthod 2013;18(5):147-74.

13. William P, Henry F, David S. Contemporary Orthodontics. $4^{\text {th }}$ ed. Proffit WR, Jr. HWF, 
Sarver DM, editors. Elsevier Health Sciences; 2006. p. 176.

14. Chu SJ, Okubo S. Range and mean discordance of individual tooth width of the mandibular anterior dentition. Pract Proced Aesthet Dent 2015;35(4):313-20.

15. Khan M, Khan MA, Hussain U. Clinical crown length, width and the width/length ratio in the maxillary anterior region in a sample of mardan population. Pakistan Oral Dent J. 2015;35(4):738-41.
16. G. Richard Scott. Dental anthropology. Encycl Hum Biol 1997;3(3):175-90.

17. Adler CJ, Donlon D. Sexual dimorphism in deciduous crown traits of a European derived Australian sample. Forensic Sci Int 2010;199(13):29-37.

18. Sah S, Zhang $H$, Chang $T$, Dhungana $M$, Acharya L, Chen L. Maxillary anterior teeth dimensions and proportions in a central mainland chinese population. Chin J Dent Res 2014;17(2):117,124. 